\title{
Tribute to Ms. Kazuko Kozaki
}

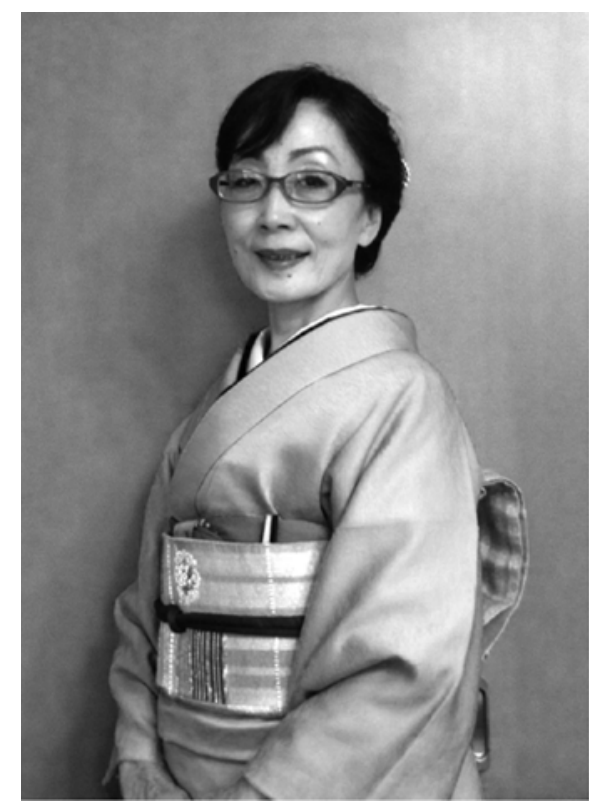

Ms. Kazuko Kozaki

Ms. Kazuko Kozaki was born on August 29, 1950*. She began work at Nagoya University on January 1, 1970, and has served as Editorial Assistant of Nagoya Mathematical Journal since April 1, 1971. She is scheduled to retire from her position on March 31, 2016, after 44 years of service. Her dedication to and meticulous efforts on behalf of the journal has been invaluable in the daily running of the journal as well as in the process of bringing the journal online and in critical contract negotiations. The Editorial Board hereby expresses its profound gratitude to Ms. Kozaki for her exquisite service and wishes her a long and happy otium.

The Editorial Board.

${ }^{*}$ Incidentally, this was also the inaugural year of Nagoya Mathematical Journal.

(C) 2016 by The Editorial Board of the Nagoya Mathematical Journal 